\title{
Million DNA Copies per Milliliter
}

National Cancer Institute

\section{Source}

National Cancer Institute. Million DNA Copies per Milliliter. NCI Thesaurus. Code C98756.

A unit of measurement equal to one million deoxyribonucleic acid (DNA) copies per unit of volume equal to one milliliter. 